\title{
Effect of Nursing Care Strategy on the Functional and Physical Abilities of Patients Following Stroke
}

\section{Zeinab Hussain $\mathrm{Ali}^{*}$}

Adult Health Nursing, Faculty of Nursing, University of Helwan, Egypt

\begin{abstract}
Stroke is an increasing problem with advancing age which may result in many physical disabilities affecting daily activities. The nurse can help stroke patients with best utilization of their remaining physical and functional abilities. This study aim was to assess the effect of application of nursing care strategies on the functional and physical abilities of patients following stroke. The study was carried out at Elnasr Insurance Hospital, in Helwan City, Egypt using a controlled quasi-experimental design. It involved 60 stroke patients equally divided into an intervention group and a control receiving the routine hospital care. The researchers developed and implemented an individualized plan of care for each patient in the intervention group based on assessment, priorities, goals, and expected outcomes. The Stroke Specific Quality of Life Scale (SS-QOL) was used to assess the effect of the intervention at three and six months follow-up. The results demonstrated significant improvements only among the study group patients at the 3 and 6-month follow-up $(p<0.001)$ in both physical and functional domains as well as in total QOL. A strong positive correlation $(r=0.87, p<0.001)$ was found between the improvements in the scores of physical and functional $Q O L$. Multivariate analysis showed that being in the study group and attending the intervention program were statistically significant independent predictors of score improvement. In conclusion, the implementation of nursing care strategies is successful in improving stroke patients' physical and functional status and QOL. It is recommended to generalize such strategies in the routine hospital care. Future research is suggested to assess the effect of such interventions on family caregivers' burden.
\end{abstract}

Keywords: Stroke; Nursing care; Functional and physical abilities

\section{Introduction}

A stroke, previously known medically as a cerebrovascular accident (CVA), is the rapidly developing loss of brain function(s) due to disturbance in the blood supply to the brain. It can be due to ischemia caused as thrombosis or embolism, or to hemorrhage [1]. The incidence of stroke increases exponentially from 30 years of age, and its etiology varies by age [2]. Thus, $95 \%$ of strokes occur in people age 45 and older, and two-thirds occur above the age of 65 [3].

Stroke may result in physical disabilities such as spasticity or hemiplagia, aphagia, dysphagia, eye problems as vision trouble seeing things off to one side, eye closure and blinking, and double vision, in addition to trouble thinking and mood disorders. Such physical disabilities lead to functional disabilities as difficulties carrying out daily activities as working, walking, talking, eating, bathing, with loss of energy, appetite, speech, and vision, in addition to pain [4-7].

Although treatment of acute stroke has the potential of reducing death and disability, the patient who is recovering from a mild stroke or who has had a recent transient ischemic attack (TIA) is at high risk for physical and functional disability, long-term hospitalization, and death [8]. Most return of function is seen in the first few months, and then improvement falls off with the "window" considered officially by U.S. state rehabilitation units and others to be closed after six months, with little chance of further improvement. Daily nursing care strategies should continue to be part of the stroke patient's routine [9].

The nurse has essential roles in helping stroke patients return to daily life activities with best utilization of their remaining physical and functional abilities. There are nursing strategies to overcome spasticity and hemiplagia through sustained stretching by various positioning [9], ice wraps or packs [10], stimulation to the antagonist muscles or vibrations [11], repetitive performance of a specific movement [12], and teaching patient to use and adapt the hemiplegic limb during functional activities to create lasting permanent changes [13]. For apahsia, the nurse can work with the family or caregivers of the patient to improve their ability to communicate using strategies as keeping distractions and noise down, not making patient feel as a child, not pretending to understand, and encouraging patient to use other ways to communicate [14]. Strategies to improve dysphagia are aimed at decreasing its complications through changing patient's posture, feeding in upright position, turning the head to the paretic side, diet modifications, and oral motor exercise [7]. Other strategies have been recommended for vision problems [15] and for thinking and mood disturbances [6].

\section{Significance of the study}

Stroke is a leading cause of death and of adult neurological disability [16]. Its incidence rate in Upper Egypt was 1.8/1000. Stroke death in Egypt reached 52,166 or $14.37 \%$ of total deaths; the age-adjusted death rate is $110.45 / 100,000$, ranking Egypt high in the world the disabilities as a result of stroke [17]. Disability affects $75 \%$ of stroke survivors enough to decrease their employability. This can be prevented through effective nursing care strategy focusing on helping patients return to normal life. This study aimed at further confirmation of the value of nursing care strategy on the functional and physical abilities of patients following stroke. Its findings would offer some evidence for modifying current standards of nursing care to include different nursing strategies

${ }^{*}$ Corresponding author: Zeinab Hussain Ali, Adult Health Nursing, Faculty of Nursing, University of Helwan, Egypt, E-mail: salmame20003@yahoo.com

Received May 20, 2013; Accepted June 19, 2013; Published June 25, 2013

Citation: Ali ZH (2013) Effect of Nursing Care Strategy on the Functional and Physical Abilities of Patients Following Stroke. J Neurol Neurophysiol S8: 006 doi:10.4172/2155-9562.S8-006

Copyright: @ 2013 Ali ZH. This is an open-access article distributed under the terms of the Creative Commons Attribution License, which permits unrestricted use, distribution, and reproduction in any medium, provided the original author and source are credited. 
for stroke patient rehabilitation, which improve patient's general health status, outcome of treatment and burden of treatment.

\section{Aim of the study}

This study aim was to assess the effect of application of nursing care strategies on the functional and physical abilities of patients following stroke. The research hypotheses were that the patients with stroke who received the nursing care strategies will 1) have better functional abilities, 2) better physical abilities, and 3) significant improvement in their quality of life (QoL) compared with those who did not received the program and was under routine hospital care.

\section{Subjects and Methods}

\section{Research design and setting}

A controlled quasi-experimental research design with pre-post and follow up assessment was utilized in carrying out this study at Elnasr Insurance Hospital, in Helwan City, Egypt.

\section{Subjects}

A convenience sample of 60 patients were recruited according to the inclusion criteria of being adult (age 18 or above), fully conscious, who suffered from a recent (within the first month) hemorrhagic stroke. These were divided into two equal groups: one for application of the intervention (study group) and the other receiving the routine hospital care (control group).

\section{Tools}

The researchers utilized an interview form, which included the Stroke Specific Quality of Life Scale (SS-QOL). The first part of the form was constructed by the researchers. It covered the bio-sociodemographic characteristics of the patient such as age, sex, education, occupation, marital status, child offspring and smoking. It also involved medical data as the recurrence of stroke, and the length of unconsciousness.

The Stroke Specific Quality of Life Scale (SS-QOL) developed by Williams et al. was modified by the researcher to assess patient's physical and functional status following stroke. It consists of two main parts. The first part covers physical abilities with six main domains [18]. The vision domain has 3 items such as trouble reaching things because of poor vision. The language domain has 5 items such as trouble speaking, trouble finding the word, etc. The mobility domain has 6 items such as trouble walking, climbing stairs, getting out of a chair, etc. The mood domain has 5 items such as discouragement about future, having little self-confidence, etc. The thinking domain has 3 items such as trouble to concentrate, remembering things, etc. The upper extremity function has 3 items such as trouble writing or typing, putting on socks, etc. Each domain item has 5 alternative selections: 1) couldn't do it at all, 2) a lot of trouble, 3) some trouble, 4) a little trouble, and 5) no trouble at all.

The second part of the scale, functional scale, consists of 6 main domains. The work /productivity domain has 3 items such as trouble doing daily work, etc. The energy domain has 5 items such as feeling tired most of the time, etc. The family roles domain has 3 items such as feeling a burden to family, etc. The social roles domain has 5 items such as not seeing as many of your friends as would like, physical condition interfering with social life, etc. The self care domain has 5 items as need help preparing food, need help eating, etc. The personality domain has 4 items as being inpatient with others, etc. Each of the 25 items has five alternative selections: 1) strongly agree, 2) moderately agree, neither agree nor disagree, moderately disagree, and strongly disagree.

Scoring: The responses to the items of each domain in the two scales are scored 1 to 5 , respectively so that a higher score indicates better function. For each scale the total score has a minimum of 25 and a maximum of 125 . A score of 76 or higher (corresponding to $60 \%$ ) indicates little or no disabilities.

\section{Methods}

Preparation: After obtaining an official permission to carry out the study from responsible authorities, the researchers started the preparation of the tool based on review of related literature. The developed tool was tested for face and content validity by a jury of five experts in the field of medical-surgical nursing and medical specialist. The panel revised the tool for clarity, relevance, applicability, comprehensiveness, and ease for implementation. According to their opinion, minor modifications were applied.

The reliability of scales in the tool was tested using the internal consistency method. It proved to be high with Cronbach's Alpha coefficients 0.995 for the physical and 0.996 for the functional scales.

Pilot study: This was conducted on 6 patients from the same hospital. It was carried out to test the feasibility and applicability of the tool, and modifications was done accordingly. Data obtained from the pilot study were not included in the actual study.

Study maneuver: The fieldwork was done though assessment, planning, implementation, and evaluation phases that extended over a period of one year from January 2012 to January 2013.

Assessment phase: The aim of this phase was to assess patient's physical, as well as to identify patient's functional needs and how to deals with these needs. Patients of both groups were interviewed individually one month following stroke in the neurosurgical department to assess their physical and functional needs using the developed tool. Researcher select patient one month following stroke because at this time patient's physical condition becomes more stable and patient at this time could be more cooperative.

Planning phase: An individualized plan of care was developed for each patient based on the finding of the assessment, priorities, goals, and expected outcomes, and a nursing strategy was formulated.

Implementation phase: Patients of the study group received the nursing care program of physical and functional care according to individualized patient's needs. Care was carried out individually by the researcher for each patient. One of the family members was asked to arrange with the patient to follow the prescribed instructions at home. The instructions included theoretical and practical parts. This was done for three consecutive months, three sessions per week, and every session lasting 60-90 minutes. The first component of the of nursing care strategy stressed mainly on teach patients and their families basic concepts about stroke as, its nature, types, causes, warning signs, and the effects of stroke on the physical and functional status. The second component focused on dealing with physical impairments. For limb disabilities as hemiplegia or spasticity, the researcher advised family to follow the strategy to help patients retain their newly learned skills since disabled people tend to avoid using impaired limbs, a behavior called learned non-use. However, the repetitive use of impaired limbs encourages brain plasticity and helps reduce disabilities.

As regards aphagia or dysphagia, the researchers worked with the patient individually to provide the suitable nursing care strategies to 
overcome or minimize the deficit. The care plan included changing body position and improving posture during eating, modifying the texture of foods that make swallowing easier, as well changing eating habits by taking small bites and chewing slowly. For vision problems, the researchers advised family to avoid deterioration through simple measures as adequate lid coverage, placing objects along the total visual field for double vision problem, use of touch or verbal cue to avoid discouragement.

To overcome thinking and mood disturbances, the researcher advised patients and their family to conserve their energy for the things that are most important, try to get good sleep at night, organize priorities, avoid rushing, and do one thing at a time. Patients were also encouraged to ask for help with the things they really need help with, and try not to get anxious and practice relaxation.

The practical component of the nursing care strategies stressed mainly on demonstrations to patients and caregiver regarding correct position during eating or drinking to avoid aspiration and facilitate swallowing process. The chin tuck compensatory technique was practiced to provide airway protection by preventing entry of liquid into the larynx. Other practices included how to change from one kind of movement to another, and rehearsing complex movements that require a great deal of coordination and balance, such as walking up or down stairs or moving safely between obstacles. In this part of the intervention, each patient was assessed if he/she followed the prescribed instructions or not.

Both study and control groups were followed up three times weekly. The study group received the intervention, while the control group patients were under routine hospital care.

Evaluation phase: Each patient in the study and control groups was evaluated three times during the study period using the study tool. The first was the baseline at the beginning of the study. Then for evaluation of the effectiveness of the intervention, re-assessments were done after three and six months post implementation of the nursing care strategies using the same tool.

\section{Ethical considerations}

An informed consent form was signed by each participant before collecting any data. The form explains the study aim in a simple and clear manner to be understood by common people. No harmful maneuvers were performed or used, and no foreseen hazards were anticipated from conducting the study on these patients. Participants were informed about their right to withdraw from the study at any time without giving any reason. Data were considered confidential and not be used outside this study without patient's approval.

\section{Statistical analysis}

Data entry and statistical analysis were done using SPSS 16.0 statistical software package. Quantitative continuous data were compared using Student t-test in case of comparisons between two groups. When normal distribution of the data could not be assumed, the non-parametric Mann Whitney test was used instead. QOL scores were compared using the non-parametric Kruskal-Wallis test for multiple group comparisons. Qualitative categorical variables were compared using chi-square test. Whenever the expected values in one or more of the cells in a $2 \times 2$ tables was less than 5, Fisher exact test was used instead. Pearson correlation analysis was used for assessment of the inter-relationships among scores. In order to identify the independent predictors of QOL scores, multiple linear regression analysis was used after testing for normal distribution and homoscedasticity, and analysis of variance for the full regression models was done. Statistical significance was considered at $\mathrm{p}$-value $<0.05$.

\section{Results}

The personal characteristics of the patients in the study and control groups are similar (Table 1). They have a mean age around 45 , with more women in the control group $(66.7 \%)$ than in the study group (53.3\%), although the difference is not statistically significant. The majority of the patients in both groups is married and has children, and is non-smokers. More patients in the study group are working (66.7\%) compared with the control group (43.3\%), but with no statistically significant difference. As for the disease characteristics, the majority of both groups have no recurrence, but the mean time of unconsciousness is lower in the study $(35.7 \pm 37.6)$ than in the control $(101.9 \pm 93.0)$ group, $\mathrm{p}<0.001$.

The assessment of physical and functional disabilities in the two groups (Table 2) demonstrates that none of the patients in either group has no/little disabilities in any of the domains. The only exception is with vision in both groups, and language in one of the patients in the study group with no statistically significant differences between the two groups. In total, all patients in both groups have moderate to high disability. At the 3-month post-intervention phase, statistically significant improvements are revealed only among the study group

\begin{tabular}{|c|c|c|c|c|c|c|}
\hline & \multicolumn{4}{|c|}{ Group } & \multirow{3}{*}{$\begin{array}{l}\mathrm{X}^{2} \\
\text { Test }\end{array}$} & \multirow{3}{*}{$\mathrm{p}$-value } \\
\hline & \multicolumn{2}{|c|}{ Study $(n=30)$} & \multicolumn{2}{|c|}{ Control $(n=30)$} & & \\
\hline & No. & $\%$ & No. & $\%$ & & \\
\hline \multicolumn{7}{|l|}{ Age (years): } \\
\hline$<40$ & 10 & 33.3 & 11 & 36.7 & & \\
\hline $40+$ & 20 & 66.7 & 19 & 63.3 & & \\
\hline Range & \multicolumn{2}{|c|}{$22.0-62.0$} & \multicolumn{2}{|c|}{$20.0-65.0$} & & \\
\hline Mean $\pm S D$ & \multicolumn{2}{|c|}{$46.2 \pm 10.5$} & \multicolumn{2}{|c|}{$43.0 \pm 11.8$} & $t=1.043$ & 0.55 \\
\hline \multicolumn{7}{|l|}{ Gender: } \\
\hline Male & 14 & 46.7 & 10 & 33.3 & & \\
\hline Female & 16 & 53.3 & 20 & 66.7 & 1.11 & 0.29 \\
\hline \multicolumn{7}{|l|}{ Job status: } \\
\hline Housewife/retired & 10 & 33.3 & 17 & 56.7 & & \\
\hline Working & 20 & 66.7 & 13 & 43.3 & 3.30 & 0.07 \\
\hline \multicolumn{7}{|l|}{ Marital status: } \\
\hline Single & 1 & 3.3 & 3 & 10.0 & & \\
\hline Married & 29 & 96.7 & 27 & 90.0 & Fisher & 0.61 \\
\hline \multicolumn{7}{|l|}{$\begin{array}{l}\text { Have children } \\
\text { (married): }\end{array}$} \\
\hline No & 6 & 20.0 & 3 & 10.0 & & \\
\hline Yes & 23 & 76.7 & 27 & 90.0 & Fisher & 0.47 \\
\hline \multicolumn{7}{|l|}{ Smoking: } \\
\hline No & 22 & 73.3 & 25 & 83.3 & & \\
\hline Yes & 8 & 26.7 & 5 & 16.7 & 0.88 & 0.35 \\
\hline \multicolumn{7}{|l|}{$\begin{array}{l}\text { Duration of } \\
\text { unconsciousness } \\
\text { (hours): }\end{array}$} \\
\hline$<24$ & 18 & 60.0 & 7 & 23.3 & & \\
\hline $24+$ & 12 & 40.0 & 23 & 76.7 & & \\
\hline Range & \multicolumn{2}{|c|}{$2.0-168.0$} & \multicolumn{2}{|c|}{$8.0-360.0$} & & \\
\hline Mean $\pm S D$ & \multicolumn{2}{|c|}{$35.7 \pm 37.6$} & \multicolumn{2}{|c|}{$101.9 \pm 93.0$} & $U=13.396$ & $<0.001^{*}$ \\
\hline \multicolumn{7}{|l|}{ Recurrent stroke: } \\
\hline No & 24 & 80.0 & 29 & 96.7 & & \\
\hline Yes & 6 & 20.0 & 1 & 3.3 & Fisher & 0.10 \\
\hline
\end{tabular}

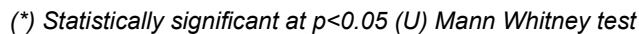

Table 1: Personal and disease characteristics of stroke patients in the study and control groups. 
Citation: Ali ZH (2013) Effect of Nursing Care Strategy on the Functional and Physical Abilities of Patients Following Stroke. J Neurol Neurophysiol S8: 006. doi:10.4172/2155-9562.S8-006

Page 4 of 6

patients, reaching $93.3 \%$ with little or no disability in mobility and personality issues. In the control group, the significant improvement was only in vision, with only very little improvements in other domains. In total, $83.3 \%$ of the study group patients have no/little disability, compared to none in the control group $(\mathrm{p}<0.001)$. The improvements in the study group continued at the 6-month follow-up, reaching $100 \%$ in many of the domains, whereas slow improvements are shown in the control group. Totally, only one patient (3.3\%) in the study group has moderate to high disability at this phase, whereas only two patients $(6.7 \%)$ in the control group have little/no disability $(\mathrm{p}<0.001)$.

Table 3 points to statistically improvement in the Quality of life (QOL) scores among patients in the study and control groups through the intervention phases $(\mathrm{p}<0.001)$. This is noticed in both physical and functional domains as well as in total QOL. However, the improvement in the study group is more prominent, rising from a mean baseline of 23.60 to a 6 -month follow-up mean of 90.09 . The corresponding figures for the control group are 22.22 and 35.03. Figure 1 illustrates a statistically significant strong positive correlation $(\mathrm{r}=0.87)$ between the improvements in the scores of physical and functional QOL.

In multivariate analysis (Table 4), the statistically significant independent predictors of the baseline pre-intervention QOL score are the patient's age (negative predictor) and the married status (positive predictor). As for the improvement in QOL score throughout the intervention, the same table indicates that being in the study group and attending the intervention program are the statistically significant independent predictors of score improvement. As revealed by the value of $r$-square, the model explains $71 \%$ of the improvement in the score. Other personal factors and the duration of unconsciousness have no effect on the improvement in QOL score.

\section{Discussion}

Physical and functional impairment following stroke are considered the most challenging for these patients, hindering their QOL. The present study tested the hypothesis that the patients with stroke who

\begin{tabular}{|c|c|c|c|c|c|c|c|c|c|}
\hline & \multicolumn{9}{|c|}{ Percent with little/no disability } \\
\hline & \multicolumn{3}{|c|}{ Pre } & \multicolumn{3}{|c|}{ FU (3-month) } & \multicolumn{3}{|c|}{ FU (6-month) } \\
\hline & Study & Control & $\mathrm{P}$ & Study & Control & $\mathrm{P}$ & Study & Control & $\mathrm{P}$ \\
\hline \multicolumn{10}{|l|}{ Physical disability: } \\
\hline Vision & 23.3 & 36.7 & 0.26 & 80.0 & 50.0 & $0.01^{*}$ & 100.0 & 50.0 & $<0.001^{*}$ \\
\hline Language & 3.3 & 0.0 & 1.00 & 90.0 & 0.0 & $<0.001^{*}$ & 100.0 & 13.3 & $<0.001^{*}$ \\
\hline Mobility & 0.0 & 0.0 & 1.00 & 93.3 & 0.0 & $<0.001^{*}$ & 100.0 & 6.7 & $<0.001^{*}$ \\
\hline Mood & 0.0 & 0.0 & 1.00 & 90.0 & 3.3 & $<0.001^{*}$ & 96.7 & 6.7 & $<0.001^{*}$ \\
\hline Thinking & 0.0 & 0.0 & 1.00 & 90.0 & 3.3 & $<0.001^{*}$ & 100.0 & 3.3 & $<0.001^{*}$ \\
\hline Upper extremity function & 0.0 & 0.0 & 1.00 & 83.3 & 3.3 & $<0.001^{*}$ & 96.7 & 6.7 & $<0.001^{*}$ \\
\hline \multicolumn{10}{|l|}{ Total: } \\
\hline Little/no & 0.0 & 0.0 & & 83.3 & 0.0 & & 100.0 & 6.7 & \\
\hline Moderate/high & 100.0 & 100.0 & 1.00 & 16.7 & 100.0 & $<0.001^{*}$ & 0.0 & 93.3 & $<0.001^{*}$ \\
\hline \multicolumn{10}{|l|}{ Functional disability: } \\
\hline Work/productivity & 0.0 & 0.0 & 1.00 & 70.0 & 3.3 & $<0.001^{*}$ & 100.0 & 16.7 & $<0.001^{*}$ \\
\hline Energy & 0.0 & 0.0 & 1.00 & 76.7 & 3.3 & $<0.001^{*}$ & 100.0 & 10.0 & $<0.001^{*}$ \\
\hline Family roles & 0.0 & 0.0 & 1.00 & 80.0 & 3.3 & $<0.001^{*}$ & 96.7 & 6.7 & $<0.001^{*}$ \\
\hline Social roles & 0.0 & 0.0 & 1.00 & 70.0 & 3.3 & $<0.001^{*}$ & 96.7 & 6.7 & $<0.001^{*}$ \\
\hline Self-care & 0.0 & 0.0 & 1.00 & 90.0 & 3.3 & $<0.001^{*}$ & 96.7 & 6.7 & $<0.001^{*}$ \\
\hline Personality & 0.0 & 0.0 & 1.00 & 93.3 & 3.3 & $<0.001^{*}$ & 96.7 & 6.7 & $<0.001^{*}$ \\
\hline \multicolumn{10}{|l|}{ Total: } \\
\hline Little/no & 0.0 & 0.0 & & 80.0 & 0.0 & & 96.7 & 6.7 & \\
\hline Moderate/high & 100.0 & 100.0 & 1.00 & 20.0 & 100.0 & $<0.001^{*}$ & 3.3 & 93.3 & $<0.001^{*}$ \\
\hline \multicolumn{10}{|l|}{ Total disability: } \\
\hline Little/no & 0.0 & 0.0 & & 83.3 & 0.0 & & 96.7 & 6.7 & \\
\hline Moderate/high & 100.0 & 100.0 & 1.00 & 16.7 & 100.0 & $<0.001^{*}$ & 3.3 & 93.3 & $<0.001^{*}$ \\
\hline
\end{tabular}

(*) Statistically significant at $p<0.05$

Table 2: Comparison of disability (QOL scale) among patients in the study and control groups throughout the intervention phases.

\begin{tabular}{|c|c|c|c|c|c|c|c|c|}
\hline & \multicolumn{6}{|c|}{ Time } & \multirow{3}{*}{ Kruskal Wallis Test } & \multirow{3}{*}{$p$-value } \\
\hline & \multicolumn{2}{|c|}{ Pre $(n=30)$} & \multicolumn{2}{|c|}{ Post $(n=30)$} & \multicolumn{2}{|c|}{$\mathrm{FU}(\mathrm{n}=30)$} & & \\
\hline & Mean & SD & Mean & SD & Mean & SD & & \\
\hline \multicolumn{9}{|l|}{ Study group } \\
\hline Physical & 25.95 & 7.45 & 78.37 & 16.07 & 91.95 & 9.00 & 64.72 & $<0.001^{*}$ \\
\hline Functional & 21.24 & 2.16 & 72.05 & 15.81 & 88.25 & 10.99 & 68.60 & $<0.001^{*}$ \\
\hline Total QOL & 23.60 & 4.18 & 75.22 & 14.16 & 90.09 & 8.78 & 67.42 & $<0.001^{*}$ \\
\hline \multicolumn{9}{|l|}{ Control group } \\
\hline Physical & 23.63 & 4.16 & 32.28 & 8.44 & 36.12 & 10.45 & 31.29 & $<0.001^{*}$ \\
\hline Functional & 20.82 & 1.18 & 26.73 & 8.97 & 33.93 & 8.99 & 41.00 & $<0.001^{*}$ \\
\hline Total QOL & 22.22 & 2.24 & 29.51 & 7.71 & 35.03 & 8.99 & 42.60 & $<0.001^{*}$ \\
\hline
\end{tabular}

$\left({ }^{*}\right)$ Statistically significant at $p<0.05$

Table 3: Quality of life (QOL) scores among patients in the study and control groups throughout intervention phases. 


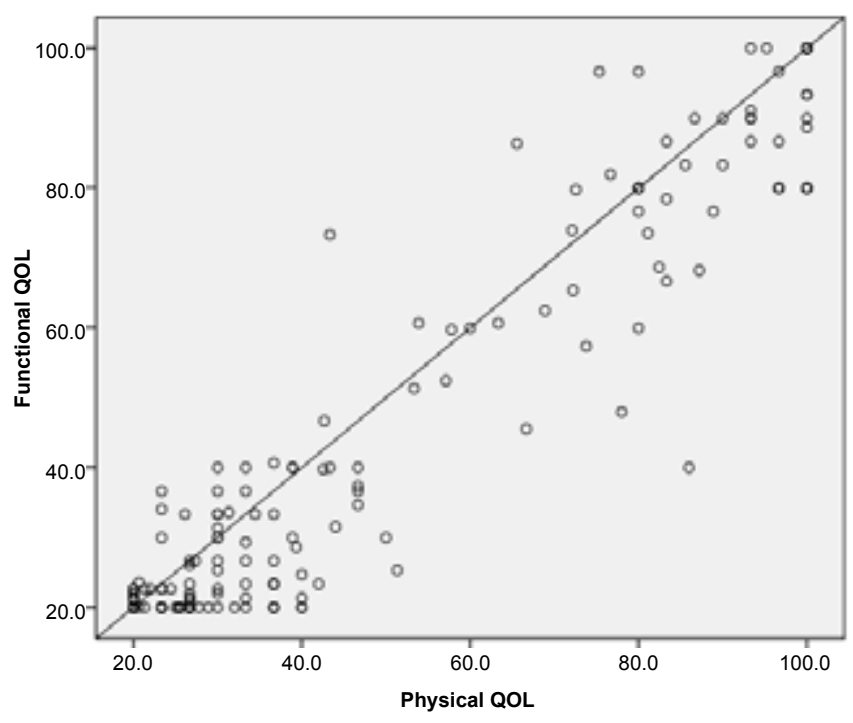

Figure 1: Correlation between physical and functional QOL.

receive planned the nursing care strategies will have better functional, physical abilities, with significant improvement in their quality of life (QoL) compared with those who did not received the program and were under routine hospital care. The findings lead to acceptance of the research hypothesis since patients in the study group had significantly higher scores at both follow-up phases, and their improvements were considerably higher compared to those in the control group.

The current study was carried out comparing an intervention and a control group. These ought to be similar in their socio-demographic characteristics to obviate the presence of any confounding on the effect of the intervention. The findings revealed that the two groups are similar in every respect, and had the characteristics commonly encountered in stroke patients, with middle to old age and more women [3,19]. Moreover, the regression analysis for the QOL at the pre-intervention phase showed that being in the study or in the control group has no effect on the QOL score.

Meanwhile, the majority of both study and control groups were not smoking, which is in disagreement with Donnan et al. who mentioned that smoking is a risk factor for stroke. The reason for the low smoking rates in the present study may be due to either denial or to the higher percentage of women in the samples [8].
The only significant difference in baseline data between the study and control groups of the current study was in the period of loss of consciousness following the attack, which was longer in the control group. Although this factor may have its impact on the disabilities that follow [20,21], the multivariate analysis showed that it had no significant independent effect on the improvement of the patients' QOL and disabilities.

According to the current study results, none of the patients in either the study of the control groups had adequate QOL (little/no disability) at the pre-intervention phase. This is quite expected since these patients were recruited within one month of the attack, which is a phase of great disablement, full dependence, and lack of adaptation and coping. In congruence with this, [22] reported high levels of physical dependence after stroke.

Only the vision domain of physical disabilities showed some adequacy at the pre-intervention phase, with approximately one-fourth of the patients in the study group, and slightly more than one-third in the control group having little or no disability with it. This might be explained by the fact that the visual problems are less common compared to mobility and speech problems following stroke. In line with this, [23] reported that only $30 \%$ of the patients with stroke suffer visual problems. Hence, [24] mentioned that the rehabilitation needs to adapt to each patient's specific needs. Therefore, if a patient has a visual field defect after stroke, this needs prompt referral for further assessment and consideration for visual rehabilitation.

The implementation of the nursing care strategies proved to be successful in effecting significant and considerable improvements in patients' physical, functional, and total QOL. This was further confirmed through multivariate analysis, which identified that the intervention and the group are the independent predictors of the QOL scores improvement. The model indicates that the intervention is effective with patients regardless their age, sex, marital status, or even the period of loss of consciousness or the recurrence of the stroke. This success might be attributed to the fact that the researcher used a multiple strategies approach in the care of the patient with stroke. These strategies are aimed at functional and physical enhancement by maximizing the independence, lifestyle, and dignity of the patient. Additionally, the involvement of the family in the intervention is an important element in its success. Therefore, the improvements were demonstrated in all the domains of the physical and functional scales.

The foregoing present study findings concerning the effectiveness of the intervention are in agreement with the report of the National

\begin{tabular}{|c|c|c|c|c|c|c|c|}
\hline & \multicolumn{2}{|c|}{ Unstandardized Coefficients } & \multirow{2}{*}{ Standardized Coefficients } & \multirow{2}{*}{ t-test } & \multirow{2}{*}{ p-value } & \multicolumn{2}{|c|}{ 95\% Confidence Interval for B } \\
\hline & B & Std. Error & & & & Lower & Upper \\
\hline \multicolumn{8}{|l|}{ Pre-intervention } \\
\hline Constant & 18.87 & 3.26 & & 5.79 & $<0.001$ & 12.35 & 25.39 \\
\hline Age & -.12 & .04 & -.39 & 2.70 & .009 & -.21 & -.03 \\
\hline Marital status (reference: single) & 4.865 & 1.97 & .360 & 2.46 & .017 & .91 & 8.80 \\
\hline
\end{tabular}

r-square $=0.13$

Model ANOVA: $F=4.39, p<0.001$

Variables entered and excluded: sex, job status, smoking, duration of unconsciousness, recurrence, group Improvement throughout intervention

\begin{tabular}{|c|c|c|c|c|c|c|c|}
\hline Constant & 73.98 & 3.91 & & 18.92 & $<0.001$ & 66.27 & 81.70 \\
\hline Group (reference: study) & -34.05 & 2.26 & -.609 & 15.09 & $<0.001$ & -38.51 & -29.59 \\
\hline Time (reference: pre) & 34.55 & 2.39 & .583 & 14.43 & $<0.001$ & 29.83 & 39.27 \\
\hline
\end{tabular}

r-square $=0.71$

Model ANOVA: $F=217.89, p<0.001$

Variables entered and excluded: age, sex, marital status, job status, smoking, duration of unconsciousness, recurrence

Table 4: Best fitting multiple linear regression model for the score of QOL (total) at the pre-intervention phase and improvement throughout intervention. 
Citation: Ali ZH (2013) Effect of Nursing Care Strategy on the Functional and Physical Abilities of Patients Following Stroke. J Neurol Neurophysiol S8: 006. doi:10.4172/2155-9562.S8-006

Institute for Health and Clinical Excellence [25]. The report mentioned that, when the nurses give more attention for physical and functional disabilities during care of stroke patients in the first months following stroke, this will lead to prevention or elimination or control of physical disabilities, enhance patient's return to normal life as soon as possible, preserve or improve overall health status, and prevent or reduce the incidence of disabilities, with consequent improvement of the QOL. On the same line, Nor et al. emphasized that using different nursing care strategies that focus on helping patients to relearn everyday activities can improve the QOL [26]. Other similar successful interventions were also previously reported [27].

Moreover, the current study findings showed a strong positive correlation between the physical and functional QOL scores. This means that the improvements in physical abilities would lead to improvements in the functional abilities, which is quite plausible. In line with this, Bandi and Ward reported that specific rehabilitative techniques, such as training, exercises, and physical manipulation of the stroke patient's body with the intent of restoring movement, balance, and coordination help stroke patient relearn simple motor activities such as walking, sitting, standing, lying down [28]. Moreover, the process of switching from one type of movement to another stimulates brain plasticity, thereby improving motor function and decreasing disability. Hence, the Post-Stroke Rehabilitation recommends improving motor control and coordination, with emphasis on repetition of specific movements for learning, developing basic movements and postures, which would lead to improvements in the functional abilities [7]. Similarly, Peppen van and Kwakkel et al. highlighted the importance of different neurological treatment approaches and exercise programs in improving functions $[29,30]$.

\section{Conclusion and recommendations}

The study results lead to the conclusion that the implementation of nursing care strategies within one month of stroke is successful in improving their physical and functional status and consequently their QOL. Therefore, it is recommended to generalize such strategies in the routine hospital care provided to stroke patients. This would decrease the incidence of complications, disabilities, and financial burden. The role of patient's family needs to be emphasized. Future research is suggested to assess the effect of such interventions on family caregivers' burden.

\section{References}

1. Sims NR, Muyderman $H(2010)$ Mitochondria, oxidative metabolism and cell death in stroke. Biochim Biophys Acta 1802: 80-91.

2. Feigin VL (2005) Stroke epidemiology in the developing world. Lancet 365 : 2160-2161.

3. Leary MC, Saver JL (2003) Annual incidence of first silent stroke in the United States: a preliminary estimate. Cerebrovasc Dis 16: $280-285$

4. Kwakkel G, van Peppen R, Wagenaar RC, Wood Dauphinee S, Richards C et al. (2004) Effects of augmented exercise therapy time after stroke: a metaanalysis. Stroke 35: 2529-2539.

5. Warlow CP, Gijn Jv, Dennis MS, Wardlaw JM, Bamford JM, et al. (2008) Stroke: Practical Management (3rd ed.). Wiley-Blackwell. ISBN 1-4051-2766-X

6. Chest, Heart \& Stroke Scotland and CHSS (2009): are operating names of The Chest, Heart \& Stroke Association Scotland, a registered Charity No. SC018761

7. Post-Stroke Rehabilitation (2011) Prepared by: Office of Communications and Public Liaison National Institute of Neurological Disorders and Stroke Nationa Institutes of Health Department of Health and Human Services Bethesda Maryland 20892 -2540 NIH Publication No. 11 -1846 April 2011
8. Donnan GA, Fisher M, Macleod M, Davis SM (2008) Stroke. Lancet 371: 16121623.

9. National Stroke Association (2011) Mobility after stroke, 8/11 BG11

10. Rimmer JH, Riley B, Creviston T, Nicola T (2000) Exercise training in a predominantly African-American group of stroke survivors. Med Sci Sports Exerc 32: 1990-1996.

11. Teixeira-Salmela LF, Olney SJ, Nadeau S, Brouwer B (1999) Muscle strengthening and physical conditioning to reduce impairment and disability in chronic stroke survivors. Arch Phys Med Rehabil 80: 1211-1218.

12. Sheean G (2002) The pathophysiology of spasticity. Eur J Neurol 9 Suppl 1: 3-9.

13. Steven C, Cramer (2011) Spasticity after Stroke: What's the Catch? 200 Health line Editorial Team, stroke complications, Reviewed by Jennifer Monti $\mathrm{MD}, \mathrm{MPH}$

14. Kantor D, Vedra P, Dugdale DC, Zieve D (2010) Communicating with someone with aphasia source: American Occupational Therapy Association, American Physical Therapy Association, American Academy of Physical Medicine and Rehabilitation, Rehabilitation Accreditation Commission, Association of Rehabilitation Nurses

15. Bailey MJ, Riddoch MJ, Crome P (2002) Treatment of visual neglect in elderly patients with stroke: a single-subject series using either a scanning and cueing strategy or a left-limb activation strategy. Phys Ther 82: 782-797.

16. Kandil MR, El-Tallawy HN, Farawez HM, Khalifa G, Ahmed MA, et al. (2006) Epidemiology of Cerebrovascular Stroke and TIA in Upper Egypt (Sohag) Relative Frequency of Stroke in Assiut University Hospital. 43

17. Taher E, Hamdy G, Abu Farha M, Awad E (2010) Predictors of stroke outcome in Egyptian patients following acute stroke, Departments of community medicine, internal medicine \& neurology Cairo University \& Ain Shams University, Egyptian Journal of Community Medicine.

18. Williams LS, Weinberger M, Harris LE, Clark DO, Biller J (1999) Developmen of a stroke-specific quality of life scale. Stroke 30: 1362-1369.

19. de Carvalho JJ, Alves MB, Viana GÁ, Machado CB, dos Santos BF, et al. (2011) Stroke epidemiology, patterns of management, and outcomes in Fortaleza, Brazil: a hospital-based multicenter prospective study. Stroke 42: 3341-3346.

20. Caplan LR (2013) Scores of scores. JAMA Neurol 70: 252-253.

21. Rowland K (2013) ACP Journal Club. The PLAN score predicted death and severe disability in patients with acute ischemic stroke. Ann Intern Med 158 JC13.

22. Langhammer B, Stanghelle JK (2003) Bobath or motor relearning programme? A follow-up one and four years post stroke. Clin Rehabil 17: 731-734.

23. Sand KM, Midelfart A, Thomassen L, Melms A, Wilhelm H, et al. (2013) Visua impairment in stroke patients--a review. Acta Neurol Scand Suppl : 52-56.

24. Luu S, Lee AW, Daly A, Chen CS (2010) Visual field defects after stroke--a practical guide for GPs. Aust Fam Physician 39: 499-503.

25. National Institute for Health and Clinical Excellence (2008) Clinical guideline. London: Stroke, p. 68.

26. Nor AM, Davis J, Sen B, Shipsey D, Louw SJ, et al. (2005) The Recognition of Stroke in the Emergency Room (ROSIER) scale: development and validation of a stroke recognition instrument. Lancet Neurol 4: 727-734.

27. Kollen BJ, Lennon S, Lyons B, Wheatley-Smith L, Scheper M, et al. (2009) The effectiveness of the Bobath concept in stroke rehabilitation: what is the evidence? Stroke 40: e89-97.

28. Bandi S, Ward AB (2012): Spasticity. In: JH Stone, M Blouin, editors International Encyclopedia of Rehabilitation. Available online: http://cirrie. buffalo.edu/encyclopedia/en/article/32/

29. Van Peppen RP, Kwakkel G, Wood-Dauphinee S, Hendriks HJ, Van der Wees PJ, et al. (2004) The impact of physical therapy on functional outcomes afte stroke: what's the evidence? Clin Rehabil 18: 833-862.

30. Kwakkel G, Kollen BJ, Wagenaar RC (2002) Long term effects of intensity of upper and lower limb training after stroke: a randomised trial. $\mathrm{J}$ Neurol Neurosurg Psychiatry 72: 473-479. 